\title{
10. Policy formulation tool use in emerging policy spheres: a developing country perspective
}

\section{Sachin Warghade}

\section{INTRODUCTION}

In many ways, policymaking in developing countries is known to be different from that in developed countries (Pye 1958; Hirschman 1975; Horowitz 1989; Corkery 1995). Apart from the fact that they lack resources and capacities in policy formulation, there is a more fundamental difference related to the political structure of developing countries. According to Pye (1958), the political sphere in the traditional societies of developing countries has remained undifferentiated from the spheres of social and personal relations. The private and group interests arising out of such relations are often the key drivers of policy formulation decisions. This hinders the development of a distinct policy sphere, thus limiting the scope for more evidence-based forms of policy formulation.

Due to this lack of a distinct policy sphere, political struggle often revolves around issues of identity and interests, themselves determined by patterns of social and personal relations, rather than the implications of alternative public policy options. In this situation, political leaders and parties enjoy political loyalty governed more by a sense of identification with a social group than by identification with a concrete policy option. This affective or expressive aspect overrides the problem-solving or public policy aspect of politics (Pye 1958). In turn, this provides space for the dominant sections of society to further their interests at the expense of the poor and marginalized.

What are the uses - both existing and potential - of policy formulation tools in such societies? Can policy formulation tools be effective in creating a space for more evidence-based policymaking and countering interest-based policymaking - as suggested in Turnpenny et al. (2009)? In other words, how does the political system in developing countries characterized by interest-based politics embedded in social and personal 
relations - react to the introduction of policy formulation tools? This chapter addresses these questions by analyzing the case of India. An important question that this chapter also addresses is whether the type of policy formulation venue selected for tool use influences the prospects for using tools to counter interest-based policymaking.

The chapter begins with a short review of the emerging prospects for the introduction of tools in the context of ongoing economic reforms in India. The use of two policy formulation tools, cost-benefit analysis (CBA) and participatory assessment - each in different policy venues (in other words, institutional locations), of varying degrees of political influence - is then analyzed with a particular focus on the design, implementation and outcome. Based on this analysis the key questions are answered in the final section.

\section{EMERGING PROSPECTS FOR TOOL USE IN DEVELOPING COUNTRIES}

Developing countries like India are on a path of rapid modernization. However, the features of traditional society still have a dominating influence on policy outlooks. Policies get formulated and determined based on narrow political considerations emanating from vested interest alignments. They emerge largely from political consensus among political and industrial elites (Mathur and Mathur 2007). Many of the development failures in developing countries are attributed to ill-conceived, inadequate and poorly implemented policies (Corkery 1995). Yet in principle, policy formulation tools can still play an important role in assisting governments to undertake systematic assessment of policy options and arrive at policies based more on evidence than vested interests.

In the past, policymaking processes outside formal political venues were non-existent. Policies were not formulated based on application of scientific tools for developing and assessing policy options. This situation prevailed until non-governmental actors started questioning public policies in India. Economic reforms over the last three to four decades gave rise to a new breed of policy influencers acting outside the formal political venues. The civil society actors involved in various social movements and struggles, fighting against the ill effects of the economic reforms, created space for participatory politics. This is contributing to the development of the field of policy analysis and especially that of policy formulation tools.

To understand these changes, it is important to study developments related to large-scale infrastructure projects, such as dams and power plants, undertaken as part of the broader economic reforms being 
implemented in comparable developing countries. Hence, we focus our attention on water sector reforms. In this sector, infrastructure projects have been regarded as necessary for fuelling growth in the era of globalization. However, such projects have created strains in the social fabric due to the disproportionate benefits they have brought to particular stakeholders. In India, the economic reforms were intensified in 1991 under the renewed and more comprehensive policy for liberalization, privatization and globalization. These reforms have further widened the rift between winners and losers (Bardhan 2009). Acquiring land, water and other forms of resources for such projects has become a significant bone of contention. The plight of 'project-affected people' has become the rallying point for several social campaigns and movements working against large infrastructure projects (Dwivedi 2006). These movements have started questioning the unilateral, closed-door, non-transparent and politically motivated nature of the policymaking process, creating space for more rational, participatory and analysis-based policymaking through the use of policy formulation tools.

Apart from its construction, recent economic reforms have begun focusing on changing the institutional design aimed at effective management and maintenance of the infrastructure created. One of the important institutional reforms pertains to the establishment of independent regulatory agencies (IRAs). It is assumed that these independent expert bodies will be able to determine policies and regulations in a more rational way by maintaining a distance from mainstream politics, and that this will provide the credibility and consistency in policy matters required for long-term planning. Thus, the IRAs are now becoming new venues for policy formulation within the boundaries of the larger policy framework determined by the government. IRAs have been set up in India in infrastructure sectors including electricity, water and telecoms.

This new venue of policy action has its own distinctive features as compared with the conventional venues of government departments headed by political leaders. IRAs comprise members who are generally expert in the particular sector in which the agency is created. These bodies are created through special legislation and accorded powers to make decisions independent of the approval of legislators. Appointments are ideally determined by a separate selection committee and not by respective government ministries or department heads. They are often given powers equivalent to a court and act as quasi-judicial bodies. Thus, the IRAs provide a venue for policy formulation that is independent of political interventions. Establishment of IRAs is an important institutional reform recommended by international financial institutions, such as the World Bank, in many developing countries including India (Dubash and Morgan 2012). 
The legitimacy of such non-majoritarian bodies hinges on 'procedural robustness' (Dubash 2008, p. 46). Participatory tools are an integral part of procedural legitimacy required by these independent bodies in formulating regulations. Being composed mainly of experts, the IRA is also seen as a technocratic form of policymaking venue. With the independent regulation model at a nascent stage in India, it is important to see what change this new venue could bring with respect to application of policy formulation tools.

India may be regarded as at a stage of evolution from formal democratic system to more meaningful and participative democracy (Mathur 2001). The erstwhile closed-door and centralized policymaking is being challenged with the demand for more open, transparent and participatory practices. In this transition phase, it is important to understand and assess the role of policy formulation tools in relation to the old and new policy venues. For this we turn to the cases of tool use in water policy formulation in two different venues: one government-led (cost-benefit analysis and participatory tool) and the other IRA-led (participatory tool).

\section{TOOL USE BY GOVERNMENT MINISTRIES}

Broader policy analysis has received less attention compared with routine public administration for reasons clearly related to the nature of policymaking in India. The public administrators, or civil service officials, provide the analytical and intellectual back-up to political leaders for developing and analyzing policy options. Public administrators are at the centre-stage of policy analysis and not experts or bodies outside the formal political venue (Sapru 2004). Thus, the policy process is coordinated by government departments manned by bureaucrats and headed by a Minister (an elected political leader). This has been the most prominent venue for policy formulation in India. The Minister heading the department has control over the appointments and transfer of public administrators. Hence, the Minister commands considerable influence on administrative procedures and outcomes. This type of venue is hereafter referred to as government-led. The following subsections discuss the cases of tool use under this particular policy venue.

\section{Cost-Benefit Analysis in Dam Building Policy}

Cost-benefit analysis (CBA) is one of the oldest and most commonly used policy formulation tools in India. Although also used for project evaluation and approval, it has a strong bearing on the overall policy related to 
publicly funded infrastructure projects. This experience will have a bearing on the future use of tools in policy formulation. Hence, for these reasons, it is important to review the use of CBA.

\section{The design of CBA}

Under British rule, dam projects were largely undertaken for returns in the form of revenue to the government, although a few projects were also undertaken specifically for drought mitigation (Singh 1997). The main criterion for undertaking projects was financial return, typically assessed by calculating internal rate of return (Iyer 2003; Singh 1997). This was a stringent criterion for assessing projects and helped in maintaining financial discipline in project planning and execution (Singh 1997). In the post-independence period, the Government of India followed a less stringent approach to project appraisal. Its approach was based on a simple cost-benefit analysis where the benefits are measured in terms of the net benefits of irrigation accruing to farmers and thereby to the economy. Costs represented only the direct cost for constructing the dam (Iyer 2003).

The less stringent design of CBA for dam projects was certainly beneficial for farmers who otherwise would have not benefitted from irrigation. Hence, it was referred to as a 'social CBA' (Singh 1997). But the main question was about distribution of these benefits. The social CBA was not a comprehensive socio-economic analysis. It did not include the full cost associated with resettlement of project-affected people and environmental damage. Had these costs been included in the design of the tool then many projects that exist today would have been rendered unviable. Hence, the design was only partly 'social'.

\section{The execution of CBA}

The less stringent design and narrow scope of CBA led to a shrinking of the role of evidence and created space for vested interests to penetrate the tool execution process. In the absence of the criterion of rate of return, there remains no accountability on project implementers to ensure that proposed benefits have accrued. No accounting procedures are required for monitoring the rate of return. Thus, the less stringent design of CBA adopted for dam appraisal and approval has made it liable to political manipulation or distortion (Iyer 2003), either direct or indirect.

One of the common manipulations while executing CBA is to understate the costs and overstate the benefits by exploiting the gaps and uncertainties that prevail in calculating future agricultural prices or costs. Here, calculations are not done as meticulously as they could be, so as not to render the project unviable. There have been instances where too many projects get cleared in a single meeting of the reviewers of CBAs 
of particular projects (Iyer 2003). There are cases in which the project costs stated during the appraisal have been revised to a very large extent after a project has been approved (Pallavi 2012). There is no system for fresh appraisal of projects after such cost escalations. This has fuelled allegations of corruption against Ministers in the Water and Resources Department (WRD).

There are pressures on government engineers to select sites for dam projects such that the political constituency of the particular political leader gets the highest benefits, irrespective of the results of the CBA. This in turn would strengthen the political domination of the leader in question. The bureaucrats and the government engineers have to yield to the pressure and select sites that are politically favourable for the leader. ${ }^{1}$ Thus, vested interests prevail over evidence in such cases.

The design of the CBA and its execution is a closed-door process. The policy formulation venue is controlled by government bureaucrats and political leaders. There is no participation of stakeholders, nor is consideration given to alternative water management options to the dam project, such as small-scale watershed conservation and development. This has been the major concern raised by various social movements opposing dam projects on the basis of negative social and environmental impacts.

\section{The outcomes of CBA}

Making the criteria for evaluation relatively lax has made it possible for government to undertake dam projects at a very large scale. This activity has fuelled the growth in large-scale irrigated cash crops and agroindustrialization (Singh 1997), creating deep-rooted inequities between upstream and downstream communities. It became the central point of argument for various social movements demanding justice for the people who lost their lands and livelihood resources such as forests and river flows.

The second most important aspect of inequitable benefits is related to the huge capital investments made through public funds. The policy of building dams has received excessive focus from government at the cost of attention to other welfare efforts, especially those required for drought-prone regions and dry-land farmers. For example, irrigated agriculture in the plains has benefitted at the cost of lower budget allocation to development of the rain-fed and drought-prone regions. Water meant for the benefit of farmers in the plains is now being reallocated for urbanindustrial growth (as discussed further below). This shows that there has been an implicit political process that has facilitated building of such dams for the benefit of only selected sections of society. In other words, the way in which CBA has been used within the government-led policy venue has played a vital role in the inequitable distribution of benefits. 


\section{The Use of Participatory Tools in Water Allocation Policy}

There are several studies suggesting that public investment in dams has not led to expected returns either in terms of government revenues or farm productivity (Singh 1997; Dharmadhikary et al. 2005). However, this did not persuade the state governments to stop the policy of building dams during the first phase of economic reforms. In fact, the budgetary allocation for constructing, operationalizing and maintaining dams has kept on increasing. The revenue receipts from water charges were not adequate to support the budgetary allocation. Financial constraints were evident. This is why the process of the second phase of reforms was undertaken with technical and financial support from international financial institutions like the World Bank. The focus was now on institutional reforms, including among other things the establishment of an IRA, rationalizing of water tariffs and creation of a system of tradable water rights (World Bank 2005).

The State of Maharashtra was one of the first to begin with this type of reform process in 2002-2003. The World Bank was the 'knowledge partner' in this process. The important reforms included adoption of a State Water Policy (SWP) and establishment of the Maharashtra Water Resources Regulatory Authority (MWRRA). Formulation of this policy framework began in 2002. While the SWP was formulated and adopted by the Government in 2003, the MWRRA Act was passed in 2005. This is the point where an attempt was being made to develop a distinct policy sphere, in which decisions could be made based on evidence rather than vested interests.

Consultation with stakeholders and the public has been the modus operandi of World Bank-led reform processes. Hence, participatory tools were used in various policy formulation stages under a government-led venue. In this case, stakeholder consultation workshops were conducted by the Water Resources Department (WRD). Headed by a Minister, it has all the characteristics of a government-led policy venue.

\section{Key issues in water allocation policy}

India's dams are a vital source of water due to the seasonal (monsoon) pattern of rainfall. In line with the official policy of central government, water for industrial use has been accorded lower priority than domestic and agricultural use (Government of India 1987; 2002). This was in line with the policy to protect and promote agro-based livelihoods for rural prosperity and sustainability. Policies were implicitly shaped by the notion of water as a 'social good'. However, the increasing international discourse around water as an 'economic good' started having its influence on water policy in India. Thus, water for the high income-generating activities associated 
with urban-industrial growth came to be seen as important for realizing the greater economic value of water. Thus, the Government of Maharashtra, in contradiction of central government policy, proposed that industry should be given higher priority than agriculture for water allocation.

The World Bank prescription was to assign water rights to users in the form of 'tradable entitlements'. It was claimed that the farmers could voluntarily transfer the water entitlements to industries at an acceptable compensation determined by the market. This was seen as an 'equitable' policy for water allocation (World Bank 2005). It is interesting to see the use of tools in the formulation of these policy proposals and how it impacted the fate of these policies.

\section{Tool design for water allocation policy}

The use of participatory tools for the formulation of the SWP and MWRRA Act was not mandatory by any law. Tool design and execution were solely a matter for the WRD. In light of the radical changes that the reforms were attempting, it was expected that the participatory tool would be designed meticulously with adequate provision of transparency, accountability and effective participation. But in reality, the design of the participatory tool was not undertaken systematically.

Consultation workshops - one at the state level and three at the lower regional level - were organized. These were severely inadequate for representation let alone direct participation of the vast majority of the rural populations that would be affected by the reforms. There was no consideration given to adequate publicity for the consultation events and related documents. Nor was a mechanism decided for publishing a 'reasoned report' that would compile all the policy options suggested by the participants in the consultations and provide assessment and considerations given by government for each of the options.

\section{Tool execution for water allocation policy}

The consultation workshops were not held as public events. Only selected people from the government and non-governmental sectors were invited. It was observed that the majority of participants were government officials. These workshops were presided over by the political leaders and Ministers, including the Minister with responsibility for the WRD which was in charge of implementing the participatory tool. The people who were selected as invited speakers mostly represented government agencies. ${ }^{2}$

A senior social activist referred to these consultation workshops as 'stage-managed events'. The workshops were managed and dominated by the presence of Ministers and officials sitting on the stage or dais during the event. The seating arrangement on the stage made the event look 
like a government-led discussion with less importance given to the nongovernment participants. The opening speeches by the Ministers created a favourable tone for the policy proposals, which was further amplified by the invited participants. Very few critical voices were heard in the workshops. This arrangement of space and the nature of invitees provided ample opportunities to override the evidence-based arguments provided by some of the participants and instead further arguments in the interests of the dominant political stakeholders.

One such evidence-based argument was made by the representatives of the social movements in Maharashtra. Based on the facts related to the existing inequity in the state, these representatives proposed an alternative water allocation policy based on a more inclusive principle of equity. This proposal was based on the principle of distribution of equal shares of water to all in the particular river basin or sub-basin, irrespective of whether individuals were landowners or not. This would of course benefit the landless rural community which has been at the receiving end of injustices caused by the age-old 'caste system' in India that has restricted land ownership to only a few upper-caste communities. The demand for such an equitable allocation policy came from actual community-based experiments and advocacy developed over the years by a group of activists and community organizations; the water rights movement in the state is spearheaded by several grass-roots organizations including the Shramik Mukti Dal organization. It was expected that this demand would be seriously considered since the benefits accruing were based on evidence coming from actual ground-level experiments and advocacy efforts.

However, in their opening speeches the political leaders including the Minister of the WRD strongly supported the reforms towards giving higher priority to industry in water allocation. This argument was made on the basis of the higher economic growth in the form of jobs and personal income that industries can bring for citizens. However, no concrete evidence was put forward in favour of this argument. The dominant groups were successful in ensuring that the opponents of reforms did not get adequate space to raise their demands and arguments.

It should be noted that in the same consultation process, the government began showcasing 'equity' as the primary principle for water allocation to be adopted in the MWRRA bill. During consultations, legal provisions were promised to ensure water rights for farmers in the form of entitlements. The emphasis on 'equity' was seen as an important change in the policy proposal achieved by the activists and organizations promoting public interest. But the operational definition of equity was narrow and ensured water only to agriculture landholders. At the same time it was proposed to provide higher priority for water allocation to industries as 
compared with farmers. Thus, considerable confusion and obscurity was created in the allocation policy, and especially in priorities for allocation (Wagle et al. 2012).

\section{The outcome of using tools}

The confusion and obscurity in allocation policy is evident from the contradictory provisions in the related policy instruments. On the one hand a higher priority was accorded to industrial as compared with agricultural water use in the SWP (Government of Maharashtra 2003). On the other hand the MWRRA Act provided for equitable water distribution in the form of assurance of water entitlements to each farmer in the command area (the area in which the benefits are experienced) of the dam. The principle of allocating water to the landless remained unaccepted.

The MWRRA Act is legally enforceable while the SWP was just a policy statement without the force of a law. The SWP was passed by the government in 2003 and the MWRRA Act came into force in 2005. So it was expected that the Act would supersede the provisions in the SWP which accorded higher priority to industrial water use. Based on this it was expected that the farmers should get their due rights in the form of water entitlements. However, in reality these provisions in the law were bypassed by the Minister for WRD while making decisions on water reallocations after the MWRRA law had passed. The Minister continued using the pre-MWRRA mechanism of re-allocating water from irrigation to non-irrigation purposes without any public hearing or compensation to affected farmers. In total, the Ministerial committee reallocated about 2000 million cubic metres of water from 51 different dams, leading to a reduction of 313196 ha of irrigation. Out of this reallocation, 54 per cent was for the urban and domestic sector and 46 per cent was for the industrial sector. ${ }^{3}$ Thus, the outcome of the participatory tool - in the form of acceptance of the principle of 'equity' - was not adhered to by the political leaders who were involved in influencing the policy formulation process. Thus, tool use during formulation of these policies was not completely successful in countering the vested interests.

\section{TOOL USE BY INDEPENDENT REGULATORY AUTHORITIES}

The MWRRA Act of 2005 gave birth to a new and untested policy venue of an IRA in a highly politicized sector: water. As mentioned in the introductory section, an IRA is an autonomous venue for policy action. Use of tools for policy formulation by a quasi-judicial IRA could 
be expected to giver higher importance to evidence-based analysis and arguments.

The Act empowered the regulatory authority to formulate and decide regulations for determining water tariffs. The focus of the process was on determining the tariff for bulk water supply. Bulk water users were identified as domestic, industrial and agricultural. The regulator initiated the process of formulating regulations in 2008. The law mandated the regulator to apply participatory tools for formulating these regulations.

\section{The Design of the Participatory Tool}

MWRRA decided to appoint a consultant to develop an approach for tariff regulations. Terms of Reference (ToR) were prepared for deciding the scope of the consultancy assignment. Among other things, the scope consisted of designing the process of formulating regulations, including the design of the participatory tool to be adopted.

The regulator initiated the consultation process right at the stage of finalizing the ToR. The ToR were circulated for comments to a select audience comprising government officials, NGOs and experts. The key features finally accepted as the design of the participatory tool included:

1. Regional-level (below state-level) public consultation meetings to be held for adequate representation from different parts of the state;

2. Publication and dissemination of consultation documents to be made available in English as well as in the local Marathi language;

3. Meetings to be open for participation by all those stakeholders affected by the water tariff to be determined;

4. Meeting invitations to be publicized in widely circulated newspapers at a prominent place;

5. All comments, options and recommendations made by the participants should be submitted to the IRA in written form;

6. 'Conduct of Business Regulations' to be prepared and enforced before initiating the consultative process so that there is transparency in, and commitment to, the overall process.

However, there were several important recommendations related to tool design which were not accepted by the regulator. The participants in the consultation on the ToR suggested that the regulator should show the impacts related to increase or decrease in the tariff based on various criteria suggested for tariff determination. But the same was not accepted in the final design. Other recommendations not accepted in the final design of the participatory tool included, among others (Prayas 2009): 
1. Allowing verbal comments to be video recorded and used for assessment of the policy options - necessary for illiterate and less articulate stakeholders, especially farmers.

2. Publication of a reasoned report comprising all the possible regulatory options suggested by the stakeholders. Such a report should also provide explanation of why certain policy options were accepted or rejected by the regulator in its final decision.

3. Formation of a 'stakeholder review committee' to provide inputs in the form of review of the ongoing participatory process.

4. Use of 'technical validation' as a tool to assess the validity of data to be used for determining tariffs.

\section{The Execution of the Participatory Tool}

The process of policy formulation started on a positive note due to concrete efforts put in to designing of the tool (as set out in the ToR). However, the implementation did not progress as per the provisions of the ToR. The analysis of adherence to the ToR suggested that almost 53 per cent of its provisions were not adhered to (Prayas 2009). For example, the 'Conduct of Business Regulations' were not prepared before initiating the consultation process. This important aspect of procedural commitment was ignored. The approach paper published for consultation was initially available only in English. After several objections by civil society organizations a short summary of the 300 page approach paper was prepared in the local language by the IRA. However, this summary was highly inadequate in conveying all the important aspects of the policy proposal. The civil society organizations then voluntarily prepared a small booklet on the proposal and disseminated widely among farmers and other marginalized communities.

Four stakeholder consultation meetings on the approach paper were announced by MWRRA. The policy proposed in the approach was found to be substantively inadequate by the civil society groups. A group of stakeholders comprising experts, NGOs and farmer organizations came together as a loosely held coalition of civil society actors (hereafter referred as the coalition). The coalition provided a policy option in the form of 'equity' and 'rights-based' approach to tariff determination. They emphasized criteria of 'minimum tariff for water required for life and livelihood' (so-called 'lifeline and livelihood tariff') and overall adherence to the principle of 'affordability'. Contrary to this demand for a 'social tariff' approach, the proposal prepared by the consultant was largely based on the principle of rationalizing tariffs based on economic principles such as reduction of cross-subsidy. 
The methodology suggested by the consultant for assessing tariff options and determination of final tariffs was based on the task of assigning weights. A set of criteria were identified for apportioning costs between irrigation, industrial and domestic water users. Weights have to be assigned to these three water user categories under each criterion. However, the assignment of weight was based on the subjective judgement of the final decision maker. This cost-apportionment matrix was found to be highly objectionable by the coalition as it would provide a high level of discretion to the regulator to adjust the weights according to its subjective judgement, to arrive at a tariff. This type of design, based on subjectively arrived-at weightings, requires adequate procedures to seek preferences on weights from all concerned stakeholders in an open and transparent environment. There was no such procedure designed in the tool, leaving space for the vested interests to creep into its execution and influence the outcome. This was evident from the proposal for cross-subsidy reduction put forward by the consultant. The coalition considered the approach paper to be biased towards industry because it proposed a reduction of the prevailing tariff burden on industries and an increase of the same on agriculture. This was the outcome of particular weights assumed by the consultant in the cost-apportionment matrix. The influence of the industrial stakeholders was evident.

The method of subjective weights would mean that the weaker stakeholders would suffer if they do not get organized and raise their voice. The coalition of civil society actors played an important role in this regard. The coalition held a meeting with the IRA and recommended complete revision of the approach before initiating any further policy formulation process. It was also brought to the attention of the regulator that the four consultation meetings were inadequate for proper representation of the vast number of farmers across the state. The regulator was reluctant to accept the demand for complete revision in the approach paper but agreed to increase the number of consultation meetings from four to a total of nine. This provided an opportunity to the coalition and individual farmers to raise their voices and demand alternative 'equitable' and 'rights-based' options for tariff determination.

The nine consultation meetings provided an opportunity for open sharing, criticism and recommendation of alternative options. The regulator played a neutral role and avoided giving any judgements on the approach paper prepared by the consultant. There was no priority given to elected political leaders. This neutral position helped in facilitating open discussions in the consultation meetings and made it possible to raise several alternatives for determining water tariffs.

After this first round of consultation meetings the regulator initiated 
the process of revising the approach paper. The alternative options suggested in the consultation meetings were assessed in this process. But it was a totally closed-door process, with no opportunity for stakeholders to engage in the assessment of the options or revise the approach paper. The regulator prepared a short report on assessment of various options, including a summary of some of the main comments and suggestions received from stakeholders. Here, the regulator recorded its assessment of various comments and options suggested in consultations. It included a brief justification of why certain options were worth considering and including while others were not.

The revised approach paper came out with new criteria based on the various social considerations suggested by participants in the first round of consultations. This was a positive development for the coalition. The implicit policy of reduction of cross-subsidy adopted in the first approach paper was abandoned in the revised approach paper by altering the weights in the cost-apportionment matrix. But the methodology based on subjective assignment of weights remained untouched. Objective criteria were suggested by stakeholders but not considered in the revised approach paper. Hence, a concern was raised on the possibility of alteration of weights in the future and thereby resurfacing of the cross-subsidy reduction strategy. The proposal for an equitable and rights-based approach to tariff-setting based on criteria of 'lifeline and livelihood tariff' was not accepted.

The revised approach paper was again published for consultation. But this time the regulator decided to have only one state-level consultation meeting. This was considered inadequate by the stakeholder groups. The state-level consultation meeting was organized in the form of a panel session to be followed by open discussions. The coalition made a demand for increasing the scope of consultation on the revised approach by conducting more meetings on the revised approach paper. However, there was no response from the regulator. Seeing that the regulator was not giving any attention to their demand, the group stalled the proceedings of the panel session, bringing the meeting to a standstill for some time, until the regulator agreed to hold regional consultation meetings at six more places in the state. This enhanced the scope of the consultative process and allowed larger numbers of participants to engage and provide alternative options for tariff determination. The regulations were finalized after this round of consultations. This event throws light on the need for providing space for negotiation even within the autonomous regulatory setting. 


\section{The Policy Outcomes of Tariff Regulations}

The outcome of the participatory tool can be seen by comparing the initial draft approach paper with the final regulations for tariff determination. Considerable changes were made in the final regulations based on the comments and suggestions given in the participatory process. Concessions on water tariffs were awarded to various disadvantaged sections such as tribal communities (indigenous people), small and marginal farmers, and people affected by dam projects. The rights-based approach in the form of the 'lifeline and livelihood tariff' was not accepted.

An important aspect of regulation in a utility sector like water is the 'financial regulation' of projects and services. This pertains to regulation of the capital and other costs along with its effective use in creation and maintenance of capital assets. Ineffective regulations in this area have been responsible for various malpractices, irregularities and corruption in construction works. Recommendations were made several times in this regard by the coalition but were ignored by the IRA. This shows the influence of the vested interests associated with financial aspects of projects even in an autonomous policy venue such as an IRA.

\section{CONCLUSION}

The economic reforms sweeping across developing countries are changing the social fabric of traditional societies. Reforms that were once focused on development projects and programmes (such as building of dams) are now aiming at institutional restructuring through changes in the policy and legal frameworks in different sectors. These sectoral institutional reforms are moving 'policy' centre-stage in politics. This can be seen as the beginning of the creation of a distinct political sphere, woven around issues of public policy as against the issues of identity and interests determined by social and personal relations. This will eventually facilitate the incorporation of policy formulation tools in formal policy processes. However, the legacy of interest-based politics in developing countries continues to have an influence on the design and use of such tools. Transplantation of models from industrialized countries without cognizance of this legacy leads to the capture of policy venues and of the process of tool use by the dominant sections of the society. The case of tool use in one particular governmentled venue points towards such a capture.

The analysis of tool use in one government-led venue has shown that vested interests enjoy a high level of influence. A sophisticated and precise tool like CBA is easily manipulated in such a venue. Opening up the 
process through the use of participatory tools has provided some space for more critical analysis of policy options. It was possible to bring equity and other social considerations in the public discourse through such participatory tools. But due to the domination of political leaders and associated vested interests, the inclusion of social principles remains partial and marred by obscurity and confusion created around its operationalization. The consultation process is dominated by the political leaders through the mechanism of 'stage-managed events'. When it comes to the implementation of the policy, the obscurity created around the social principles comes as a handy tool for the political leaders to completely bypass the policy provisions related to these principles. Thus, tool use under a governmentled venue remains ineffective in countering vested interests.

The model of the independent regulatory authority (IRA) has its origin in developed countries. Transplantation of this model of independent regulation to developing countries has given rise to a new venue for tool use. The focus of tool use by IRAs in developed countries has been to ensure techno-economic rationality in policy decisions. The IRA is supposed to achieve this by keeping an arm's-length distance from the political executive. In the case of developing countries, social policy considerations are so critical that an IRA cannot remain focused purely on techno-economic rationality. The case of tool use under this new policy venue shows the potential of independent regulatory processes in countering vested interests and bringing in social policy considerations.

Tool use in an IRA-led venue has shown higher potential in countering vested interests. Unlike the 'stage-managed events' in the governmentled venue, the IRA was able to provide a neutral institutional location for the sharing of policy options and their assessment. This provided an important opportunity for civil society actors to form a coalition and represent the poor and marginalized sections in the policy formulation process. The autonomous nature of the venue ensured that the policy options presented by these social actors are heard and incorporated in the official policy assessment process. This provided the much needed space for presenting evidence in favour of a pro-poor approach to tariff policy. The tool use under the autonomous policy formulation venue was actually able to counter the dominant interests linked to the reduction of cross-subsidy. This is evident from the fact that the policy option of cross-subsidy reduction was abandoned and on top of this, new concessions in water tariffs were awarded to various disadvantaged sections of the society. 


\section{FUTURE PROSPECTS}

There are several rationales put forward for delegating powers to nonmajoritarian agencies, such as the IRA (Thatcher and Stone Sweet 2002). They largely focus on the policy outcomes in a developed country context. This chapter has suggested an important process-related rationale specifically relevant for developing countries. The process-related rationale is to provide a neutral and autonomous venue for design and implementation of policy formulation tools. Based on this rationale, the mechanism of policy formulation by autonomous agencies can be extended beyond the scope of IRA-led policymaking. An 'autonomous policy formulation venue' can be envisaged irrespective of whether the final policy decision is made by an IRA or other government agencies or Ministers. However, the cases show that there are still some barriers in this regard. Although there have been positive outcomes, the policy options related to 'rights-based' water tariffs or the option of cost regulation of water utilities were not accepted in the final policy. Hence, there are certain conditions of tool use that need to be created and maintained to achieve the objective of countering vested interests in the policy formulation process.

Considering the specific context of developing countries, we suggest four important conditions of tool use in an 'autonomous policy formulation venue'. First, there is a need to evolve systems and mechanisms for mobilization and organization of the marginalized sections so that they can effectively participate in the process of tool use. This will act to counter-balance attempts by dominant interests to capture the tool-use process. Enabling the formation of coalitions of the marginalized sections and capacity building of such groups are some of the important mechanisms that the cases in this chapter throw light on. Second, the autonomous policy venue should be backed by a robust institutional design for tool design and implementation. The design should include rules and regulations for maintaining high levels of transparency and accountability.

Third, there is a need to leave some space for enabling 'negotiations' that might be needed at different stages of tool design and implementation. Theoretically such a space for negotiation should not exist in an autonomous type of venue because of its non-majoritarian status. But the cases show that one-to-one negotiation with the IRA helped the representatives of the marginalized sections gain a stronger foothold on the design of the tool, especially in terms of increasing the intensity of the participatory consultations. Given the social-political reality of developing societies there is higher possibility that whatever system is evolved for ensuring evidence-based policy formulation, including the autonomous venue for tool use, it will eventually be captured by dominant groups. 
Thus, extra efforts are needed to even out the excess advantage of the dominant sections by providing negotiation space for the marginalized. The cases presented in this chapter show how the coalition of civil society actors played an important role in negotiating a more participatory and transparent tool design in favour of the marginalized. Thus, officially recognizing the existing coalitions as representative of this section of society, or appointing special representatives for it, are some of the mechanisms that would facilitate the development of a negotiated approach within an autonomous venue.

A fourth important condition in this regard relates to the pre-existence of a framework of social principles under which policy formulation within autonomous venues can be exercised. Such a framework may be spelled out in the country's Constitution or other legal instruments. The framework will lay down the broader principles such as equity and social justice. Without such a framework, tool use under an autonomous venue will lead to de-politicization of the policy process which might be harmful for the poor and marginalized sections of the society.

These four conditions define the features of the autonomous policy formulation venue adapted to the sociopolitical reality of developing countries. Tool use in such a venue can prove to be an effective strategy in developing countries to counter the interference of undue vested interests and promote evidence-based politics that are more pro-poor. Thus, the path to reforms in developing countries cannot be merely of 'institutional transplantation' of developed country models. Instead there is a need to undertake a fresh 'institutional design' approach to accommodate and address the problems specific to developing countries.

\section{NOTES}

1. Based on interviews with senior social activists working on rehabilitation of projectaffected people.

2. Based on interviews with social activists who participated in the consultation process.

3. Based on government data collected by Right to Information Act by the NGO PRAYAS.

\section{REFERENCES}

Bardhan, P. (2009), 'Notes on the political economy of India's tortuous transition', Economic \& Political Weekly, 5 December, 44 (49), 31-36.

Corkery, J., A. Land and J. Bossuyt (1995), 'The process of policy formulation: institutional path or institutional maze? Study based on the introduction of 
cost-sharing for education in three African countries', Policy Management Report 3, Maastricht: European Centre for Development Policy Management.

Dharmadhikary, S., S. Sheshadri and Rehmat (2005), Unravelling Bhakra: Assessing the Temple of Resurgent India: Report of a Study of the Bhakra Nangal Project, Badwani (MP): Manthan Adhyayan Kendra.

Dubash, N. (2008), 'Independent regulatory agencies: a theoretical review with reference to electricity and water in India', Economic \& Political Weekly, 43 (40), $46-54$.

Dubash, N. and B. Morgan (2012), 'Understanding the rise of the regulatory state of the South', Regulation \& Governance, 6 (3), 261-281.

Dwivedi, R. (2006), Conflict and Collective Action: The Sardar Sarovar Project in India, Routledge: New Delhi.

Government of India (1987), National Water Policy, New Delhi: Government of India, Ministry of Water Resources.

Government of India (2002), National Water Policy, New Delhi: Government of India, Ministry of Water Resources.

Government of Maharashtra (2003), Maharashtra State Water Policy 2003, Mumbai: Government of Maharashtra, India.

Hirschman, A.O. (1975), 'Policymaking and policy analysis in Latin America - a return journey', Policy Sciences, 6, 385-402.

Horowitz, D.L. (1989), 'Is there a Third-World policy process?', Policy Sciences, $22(3 / 4), 197-212$.

Iyer, R. (2003), Water: Perspectives, Issues, Concerns, Sage: New Delhi.

Mathur, K. (2001), 'Governance and alternative sources of policy advice: the case of India', in K. Weaver and P.B. Stares (eds), Guidance for Governance. Comparing Alternative Sources of Public Advice, Tokyo and Washington, DC: Japan Centre for International Exchange and Brookings Institute, pp. 207-230.

Mathur, N. and K. Mathur (2007), 'Policy analysis in India: research bases and discursive practices', in F. Fischer, G.J. Miller and M.S. Sidney (eds), Handbook of Public Policy Analysis: Theory, Politics, and Methods, Boca Raton, New York, and Oxford: CRC Press Taylor \& Francis Group, Chapter 39.

Pallavi, A. (2012), 'Maharashtra's white paper on irrigation projects fails to answer key questions', Down To Earth (3 December 2012), retrieved from http:// www.downtoearth.org.in/content/maharashtras-white-paper-irrigation-scamfails-answer-key-questions (accessed 31 November 2013).

Prayas (2009), Independent Water Regulatory Authorities in India: Analysis and Intervention, Compendium of Analytical Work by PRAYAS (2006-09), Pune, India: Prayas.

Pye, L.W. (1958), 'The non-Western political process', The Journal of Politics, 20 (3), 468-486.

Sapru, R. (2004), Public Policy: Formulation, Implementation and Evaluation, New Delhi, India: Sterling Publishers.

Singh, S. (1997), Taming the Waters: The Political Economy of Large Dams in India, Oxford: Oxford University Press.

Thatcher, M. and A. Stone Sweet (2002), 'Theory and practice of delegation to non-majoritarian institutions', West European Politics, 25 (1), 1-2.

Turnpenny, J., C.M. Radaelli, A. Jordan and K. Jacob (2009), 'The policy and politics of policy appraisal: emerging trends and new directions', Journal of European Public Policy, 16 (4), 640-653. 
Wagle, S., S. Warghade and M. Sathe (2012), 'Exploiting policy obscurity for legalising water grabbing in the era of economic reform: the case of Maharashtra, India', Water Alternatives, 5 (2), 412-430.

World Bank (2005), 'India's water economy: bracing for a turbulent future', Washington, DC: World Bank. 